\title{
Dieta flexível sob a perspectiva clínica e fisiculturista
}

- A restrição alimentar pode ser definida como uma restrição na ingestão alimentar de forma consciente;

- A restrição alimentar pode ser realizada de duas formas (estratégias): através de um "controle rígido" ou um "controle flexível";

- O controle rígido está associado a um maior índice de massa corporal, mais episódios de compulsão alimentar e escores mais altos desinibição (excessos);

- No controle flexível o indivíduo faz suas próprias escolhas alimentares e faz suas próprias compensações caso "quebre a dieta", sendo associado a um menor índice de massa corporal e menos episódios de compulsão alimentar;

- A dieta flexível foi elaborada com base nos benefícios propostos pelo controle flexível;

- A dieta flexível também é conhecida como dieta dos macronutrientes ou IIFYM (If It Fits Your Macro);

- Na dieta flexível o indivíduo não possui horários determinados para realizar as refeições;

- Na dieta flexível o indivíduo precisa apenas atingir os macronutrientes calculados na dieta ao final do dia;

- Não possuir horários determinados para as refeições (podendo gerar grandes intervalos entre refeições) ou optar por uma refeição contendo muito lipídio ou carboidrato, pode gerar potenciais prejuízos a saúde.

\section{Referências bibliográficas}

1. WESTENHOEFER, J. Dietary restraint and disinhibition: is restraint a homogeneous construct? Appetite; 16(1):45-55, 1991.

2. SMITH, C.F.; WILLIAMSON, D. A.; BRAY, G. A. et al. Flexible vs. Rigid dieting strategies: relationship with adverse behavioral outcomes. Appetite; 32(3):295-305, 1999.

3 STEWART, T.M.; WILLIAMSON, D.A.; WHITE, M.A. Rigid vs. flexible dieting: association with eating disorder symptoms in nonobese women. Appetite; 38(1): 39-44, 2002.

4 WILLIAMSON, D. A.; PERRIN, L.; BLOUIN, D. C. et al. Cognitive bias in eating disorders: interpretation of ambiguous body-related information. Eating and weight disorders: EWD; 5(3):143-151, 2000.

5 EMERSON, S. R. et al. Magnitude and Timing of the Postprandial Inflammatory Response to a High-Fat Meal in Healthy Adults: A Systematic Review. Advances in Nutrition: An International Review Journal; 8(2):213-225, 2017.

6. BANDÍN, C. et al. Meal timing affects glucose tolerance, substrate oxidation and circadian-related variables: A randomized, crossover trial. International Journal of Obesity; 39(5):828-833, 2015. 